\title{
A dissociation between two implicit conceptual tests supports the distinction between types of conceptual processing
}

\author{
ROBERTO CABEZA \\ University of Tsukuba, Tsukuba, Japan
}

\begin{abstract}
Subjects studied words in a classification task (to what categories does it belong?) or in a production task (producing associates to the word) and then completed one of two implicit memory tests-category association or free association. The classification study task and the categoryassociation test emphasize categorical relations between concepts, and the production study task and the free-association test draw on associative relations. As predicted by the transfer-appropriate processing principle, priming in the category-association test was larger for words studied under the classification task than for those studied under the production task, whereas the opposite was true in the free-association test. This crossover dissociation is the first obtained between two implicit conceptual tests, and it provides support for the claim that it is necessary to distinguish between different types of conceptual processing.
\end{abstract}

Explicit memory tests, such as recall and recognition tests, require subjects to retrieve studied items, whereas implicit memory tests do not mention the study episode, measuring memory as a facilitation to perform a seemingly unrelated task (Graf \& Schacter, 1985). In the implicit word-fragment completion test, for example, subjects are required to complete cues, such as d_n_s a with the first word that comes to their minds, and retention is observed as an enhanced probability of completing the fragments corresponding to studied words relative to nonstudied words (e.g., dinosaur). This kind of facilitation, known as priming, can be observed not only in implicit tests based on perceptual cues, such as the word-fragment completion test, but also in implicit tests based on conceptual cues, such as answering generalknowledge questions (e.g., What group of animals became extinct in prehistoric times?), the category-association test (e.g., producing examples to categories such as "reptiles"), and the free-association test (e.g., producing associations to words such as mammoth).

The distinction between implicit perceptual and implicit conceptual tests is important because they can be dissociated by different experimental manipulations (for reviews, see Roediger \& McDermott, 1993; Roediger,

This research was supported by a scholarship from the Ministry of Education and is part of a doctoral dissertation submitted to the doctoral program in psychology at the University of Tsukuba. I wish to thank Bradford Challis, Tim Curran, John Gardiner, Peter Graf, Gail Musen, Nobuo Ohta, Suparna Rajaram, Henry Roediger III, Barbara Schwartz, and two anonymous reviewers for their valuable comments about the present experiment. Correspondence concerning this article should be addressed to R. Cabeza, Rotman Research Institute, Baycrest Centre, 3650 Bathurst Street, North York, ON, Canada M6A 2E1.
Srinivas, \& Weldon, 1989). In general, perceptual manipulations, such as modality (e.g., Srinivas \& Roediger, 1990) and typography (e.g., Blaxton, 1989) shifts, affect implicit perceptual but not implicit conceptual tests, whereas conceptual manipulations, such as levels of processing (e.g., Srinivas \& Roediger, 1990), imagery (Blaxton, 1989), and list organization (Rappold \& Hashtroudi, 1991) produce the converse results. Moreover, the read/generate manipulation usually yields a double dissociation between the two types of implicit tests (e.g., Blaxton, 1989; Srinivas \& Roediger, 1990).

The procedural, or processing, view (e.g., Roediger \& Blaxton, 1987; Roediger \& McDermott, 1993; Roediger, Weldon, \& Challis, 1989) can account for the foregoing dissociations on the basis of the transfer-appropriate processing principle (memory performance is a function of the overlap between study and test operations; e.g., Morris, Bransford, \& Franks, 1977), and a distinction between perceptual and conceptual processing (e.g., Jacoby, 1983): conceptual manipulations affect implicit conceptual tests because they both emphasize conceptual processing, whereas perceptual manipulations affect perceptual tests because they both rely on perceptual processing.

Nevertheless, dissociations have also been observed between different implicit perceptual tests. Weldon and Roediger (1987) discovered that words produced more priming than pictures in the word-fragment completion test, whereas pictures yielded more priming than words in a picture-fragment identification test. Manipulating the Japanese scripts hiragana and kanji, Cabeza (in press) found that words written in hiragana generated more priming than words written in kanji in a hiraganafragment completion test, whereas the opposite occurred in a kanji-fragment completion test. The processing 
view can account for these dissociations by assuming that there are different types of perceptual processing (e.g., verbal and pictorial).

Is it also necessary to distinguish between different types of conceptual processing? Roediger and McDermott (1993) suggested that it is:

Just as we can distinguish different sorts of perceptual processes and use them to make principled predictions on implicit perceptual tests (as in Weldon and Roediger, 1987, Experiment 4), we need to make finer distinctions in the conceptual domain too. We need to distinguish further between types of perceptual processing and types of conceptual processing. (p. 118)

The idea of the existence of different types of conceptual processing would be supported by dissociations between different implicit conceptual tests, but such evidence seems to be lacking. The objective of the experiment reported in this article was to fill this void, by obtaining a dissociation between category-association and free-association tests. Although these tests are very similar (they both require subjects to generate for each cue several conceptually related words), there is one clear difference between them. The category-association test involves categorical relations between concepts (e.g., ANIMAL: $d o g$, cat, horse, cow, etc.), but the free-association test involves associative relations (e.g., ANIMAL: vegetable, life, farm, blood, etc.). The distinction between these two types of relations is supported by developmental dissociations in free recall (e.g., Bjorklund \& De Marchena, 1984; Bjorklund \& Jacobs, 1985; Frankel \& Rollins, 1986) and in different patterns of semantic priming (e.g., McCauley, Weil, \& Sperber, 1977).

In the present experiment, subjects studied words in a task emphasizing categorical relations (a classification task), or in a task underscoring associative relations (a word production task). The transfer-appropriate processing principle predicts that the classification task will generate more priming than the production task in the category-association test, whereas the converse will occur in the free-association test. Such a dissociation would support the idea that it is necessary to distinguish between types of conceptual processing.

\section{METHOD}

\section{Subjects and Design}

One hundred and twenty University of Tsukuba undergraduates participated voluntarily in the experiment. All the subjects were native speakers of Japanese, and all the materials were exclusively in Japanese (the English examples in this report are approximate translations of the originals). The design had one between-subjects factor, test type (category association, 60 subjects; free association, 60 subjects), and one within-subjects factor, type of processing during learning (classification, production, nonstudied).

\section{Materials}

The materials were 48 category-instance word pairs (e.g., religions-Islam) selected from category association norms (Akita, 1980; Ogawa, 1972). The instances were generated, within the first four answers, by about one third of the subjects in the norms. Associates for each instance word were collected in a pilot study (e.g., ISLAM: Mohammed, Arab, Mecca, prayer, Koran, mosque, turban, etc.), and three of the most common associates of each word were selected to construct the three-word cues of the free-association test (e.g., turban/ prayer/Koran). Three-word cues were used instead of one-word cues in order to obtain a higher baseline, closer to the one expected in the category-association test. The baseline level of the three-word cues was examined in two pilot studies, and the cues that were too easy (baseline above 0.50 ) or too difficult (baseline below 0.10) were modified accordingly. The set of 48 target words and corresponding cues was divided into three sets of 16 items each. Additionally, 16 words were selected from the same source or produced by the experimenter to be used as study fillers.

\section{Procedure}

The subjects received a booklet with three parts, titled "Survey 1," "Survey 2 ," and "Survey 3." The first parts were the two study tasks and the third was the test, but they were presented to the subjects as three independent "surveys" concerning the relationship between words. No memory test was mentioned; hence, learning was incidental. In Survey 1 and Survey 2, the subjects studied one block of items under a classification task and one block under a production task, with the order counterbalanced. Each block consisted of one set of targets (16 items) plus eight study fillers (three primacy; five recency). In the classification task, the subjects had to indicate under what "class or classes of things" they could classify the referent of each word (e.g., WATERMELON: fruit, vegetable, food, etc.). In the production task they had to generate associates for each word (e.g., WATERMELON: summer, red, fresh, round, etc.). Two examples were provided in each task. In both tasks, the subjects could write a maximum of four answers for each item. In the production task, they were encouraged to write at least two answers and to avoid proper nouns. The time allowed for each item was $10 \mathrm{sec}$; this was signaled by a bell, which indicated that the subjects were to move a cover sheet and start with a new item.

A few minutes after the second study task, the subjects started with the category-association test or the free-association test. The instructions for both tests were implicit: they referred only to the task at hand and did not mention any previous episode. In the category-association test, the subjects were asked to generate instances for each category name in a list (e.g., FRUIrs: orange, apple, watermelon, pineapple, etc.). In the free-association test, they were asked to generate words associated with two or three of the words of each three-word cue in a list (e.g., round/red/seeds: traffic signal, tomato, Japanese flag, watermelon, etc.). In both tests, the subjects could write a maximum of four answers for each item and were encouraged to write at least two. In the free-association test, they were instructed not to use proper nouns. Each test consisted of two sets of studied items mixed with one set of nonstudied items, in a different random order for each subject. The assignment of the three sets of items to the classification, production, and nonstudied conditions was completely counterbalanced. The time allowed for each target was $15 \mathrm{sec}$ and was paced as in the study tasks.

\section{RESULTS}

Table 1 shows the results for all the items (16 in each condition) and the results conditionalized on successful or unsuccessful processing at study (see below). The results for all items are considered first.

Priming, which was evaluated by contrasting the classification and production conditions with the nonstudied condition, was highly significant $(p<.0001)$ in all cases [category-association test: classification, $F(1,118)=$ $102.35, M S_{\mathrm{e}}=1.65$, production, $F(1,118)=69.19, M S_{\mathrm{e}}=$ 1.11; free-association test: classification, $F(1,118)=27.51$, $M S_{\mathrm{e}}=0.38$, production, $\left.F(1,118)=58.14, M S_{\mathrm{e}}=0.80\right]$.

After evaluating the significance of priming, the results of the nonstudied condition were subtracted from those of the two studied conditions, and subsequent analyses were performed on the resulting priming scores (see Figure 1). First, separate one-way analyses of vari- 


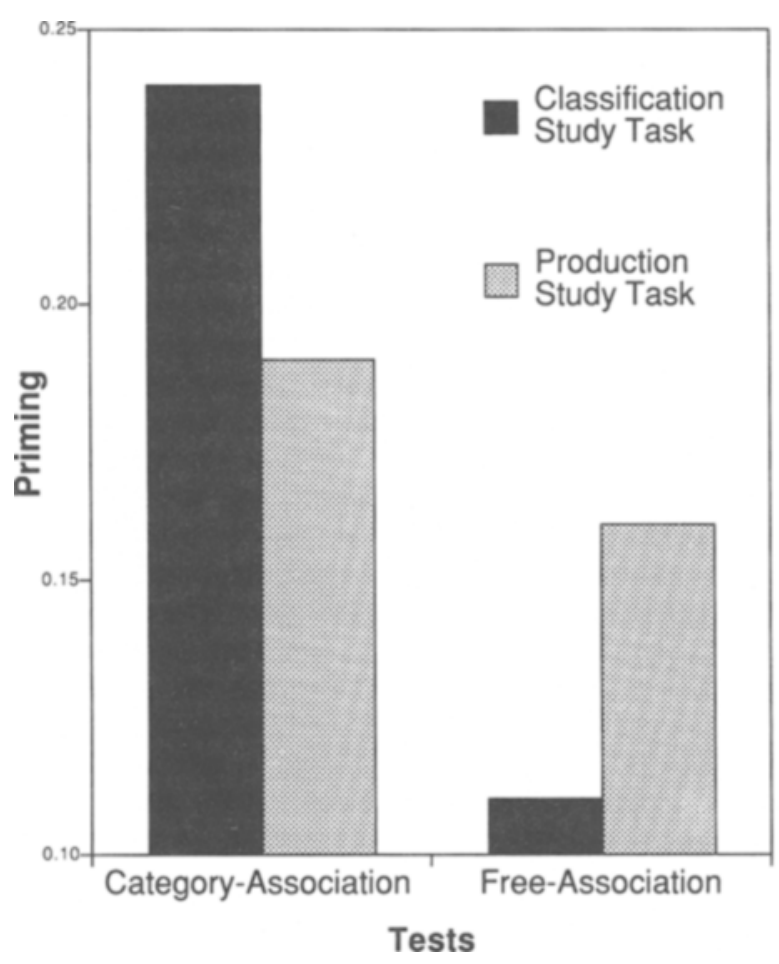

Figure 1. Effect of a classification production encoding manipulation on priming in category-association and free-association tests.

ance (ANOVAs) on each test indicated that the difference between priming in the classification and production conditions was significant in the category-association test $\left[F(1,59)=4.04, M S_{\mathrm{e}}=0.05, p<.05\right]$ and the freeassociation test $\left[F(1,59)=6.43, M S_{\mathrm{e}}=0.08, p<.02\right]$. In the category-association test, the classification study task produced reliably more priming than the production study task, whereas in the free-association test, the converse occurred. Second, a two-way ANOVA (study task $\times$ test) showed a significant main effect of test $\left[F(1,118)=6.56, M S_{\mathrm{e}}=0.34, p<.02\right]$ and, more important, a significant study task $\times$ test interaction $\left[F(1,118)=10.30, M S_{\mathrm{e}}=0.13, p=.002\right]$. Thus, the classification production manipulation reliably affected both tests in different directions.

In order to corroborate that the effect of the classification production manipulation reflected a difference between the processing of categorical and associative relations rather than other differences between the two study tasks, separate analyses were conducted for items in which the processing of categorical and associative relations at study was and was not successful (see Table 1). Successful processing of categorical relations was defined as the production of the standard category name (i.e., the one used in the category-association test) and the successful processing of associative relations as the generation of a typical association (i.e., any of the three words in the free-association cues). The probability of producing the standard category was .43 in the classification task and .10 in the production task, whereas the probability of generating a typical association was .03 in the classification task and .32 in the production task. Moreover, the main effect of study task on the category- and free-association tests and the study task $x$ test interaction were significant when the processing of categorical and associative relations at study was successful $\left[F(1,59)=5.67, M S_{\mathrm{e}}=0.74 ; F(1,59)=48.55\right.$, $M S_{\mathrm{e}}=3.81$; and $F(1,118)=37.79, M S_{\mathrm{e}}=3.96$, respectively], but nonsignificant when it was not $[F(1,59)=$ $2.16, M S_{\mathrm{e}}=0.03 ; F(1,59)=1.50, M S_{\mathrm{e}}=0.02$; and $\left.F<1\right]$. Therefore, the classification production effect can be safely attributed to a difference between the processing of categorical and associative relations.

\section{DISCUSSION}

As predicted by the transfer-appropriate processing view, the classification production manipulation produced a crossover dissociation between the category-association and free-association tests. Priming in the category-association test was larger for words studied under the classification task than for those studied under the production task, whereas the opposite occurred in the free-association test. This is the first dissociation between two implicit conceptual tests, and it supports the idea that it is necessary to distinguish between different types of conceptual processing. In particular, this dissociation buttresses a distinction between the conceptual processing of categorical relations and the conceptual processing of associative relations between words. The importance of the present results, however, does not lie on confirming this particular distinction, but on providing evidence supporting the general notion that different types of conceptual processing can be distinguished.

It is possible to argue that the present results do not show a dissociation between two types of conceptual processing, but one between two types of encoding context (categories and associates), which can be predicted by the encoding specificity principle (e.g., Tulving \& Osler, 1968). However, as in the case of previous distinctions between types of processing, the idea of different types of processing is but-

Table 1

Proportion of Target Generation in the Category- and Free-Association Tests for All Items, for Items in Which the Processing of Categorical and Associative Relations at Study Was Successful (See Explanation in the Text), and for Those in Which it Was Not

\begin{tabular}{llcccc}
\hline & & & \multicolumn{3}{c}{ Test Items } \\
\cline { 3 - 5 } \multicolumn{1}{c}{ Items Computed } & & Test & Classification & Production & Nonstudied \\
\hline All & Category association & .50 & .45 & .26 \\
Successful processing at study & Free association & .36 & .41 & .25 \\
\multirow{3}{*}{ Unsuccessful processing at study } & Category association & .60 & .44 & .26 \\
& Free association & .09 & .45 & .25 \\
& Category association & .40 & .43 & .26 \\
& Free association & .35 & .38 & .25 \\
\hline
\end{tabular}

Note-Proportions in the nonstudied condition are for all items. 
tressed by converging evidence from other research domains. The distinction between the perceptual processing of words and pictures (Weldon \& Roediger, 1987) is supported by neuropsychological evidence that these materials involve different neural structures (for a review, see Kolb \& Whishaw, 1990), and the distinction between the perceptual processing of kanji and hiragana scripts (Cabeza, in press) by the existence of aphasic, alexic, and agraphic patients that are impaired in one script but not in the other. Likewise, the distinction between the conceptual processing of categorical relations and the conceptual processing of associative relations is substantiated by several developmental dissociations, which the notion of encoding specificity cannot explain (e.g., Bjorklund \& De Marchena, 1984; Bjorklund \& Jacobs, 1985; Frankel \& Rollins, 1986; McCauley et al., 1977).

One potential problem of implicit memory tests is the uninstructed use of intentional retrieval strategies. The fact that in the present experiment the subjects sometimes generated words at study that later appeared as the cues in the tests could have increased the probability of such a complication. However, there are several reasons to think that a contamination by explicit retrieval did not occur in the present experiment. First, the implicit nature of the tests employed is supported by findings of preserved priming in amnesic patients (e.g., Gardner, Boller, Moreines, \& Butters, 1973; Graf, Shimamura, \& Squire, 1985; Shimamura \& Squire, 1984). Second, unlike what could be expected in explicit cued-recall performance, priming in these tests was not af fected by the strength of the cue-target relation. Rappold and Hashtroudi (1991) found that instances with a high frequency of production in category-association norms were better recalled than were low-frequency instances in an explicit category test, whereas priming in the category-association test was not affected. In the present experiment, the frequency of production of category instances was not manipulated directly, but it can be inferred from the baseline of nonstudied item $(0.00-0.75)$. If the subjects had interpreted the categoryassociation test as a cued-recall test, a positive correlation could be expected between the frequency of an instance and its corresponding priming, particularly in the classification condition, but this correlation was negative $(r=-.2)$. In the free-association test, the correlation between the baseline and priming in the production condition was also negative $(-.17)$. Finally, priming for items in which no test cue was generated at study was highly significant $(p<.0001)$ [categoryassociation test: classification, $F(1,118)=32.41, M S_{\mathrm{e}}=0.57$, production, $F(1,59)=48.98, M S_{\mathrm{e}}=0.86$; free-association test: classification, $F(1,59)=24.78, M S_{\mathrm{e}}=0.35$, production, $F(1,59)=37.77$, $M S_{\mathrm{e}}=0.54$.] and not reliably different from priming for items in which test cues were produced at study $(F<1)$.

Nevertheless, even if there is no reason to think that the tests were contaminated, and even if there is evidence suggesting that they were not, future experiments in which the implicit nature of tests is certified by dissociations with explicit tests with the same nominal cues (the retrieval intentionality criterion; see Schacter, Bower, \& Booker, 1989) would be beneficial.

In sum, the present experiment shows a dissociation between two implicit conceptual tests that can be interpreted as supporting the distinction between types of conceptual processing.

\section{REFERENCES}

AKITA, K. (1980). Kategori ni zokusuru go no shutsugen hindohyou. [Word frequency association norms for 50 categories]. Doushisha Daigaku Jinbungaku, 134, 42-87.

Buorklund, D. F., \& De Marchena, M. R. (1984). Developmental shifts in the basis of organization in memory: The role of associative versus categorical relatedness in children's free recall. Child Development, 55, 953-962.

BJoRKLUND, D. F., \& JACOBS, J. W. (1985). Associative and categorical processes in children's memory: The role of automaticity in the development of organization in free recall. Journal of Experimental Child Psychology, 39, 599-617.

BLAXTON, T. A. (1989). Investigating dissociations among memory measures: Support for a transfer-appropriate processing framework. Journal of Experimental Psychology: Learning, Memory, \& Cognition, 15, 657.
CABEZA, R. (in press). Investigating the mixture and subdivision of perceptual and conceptual processing in Japanese memory tests. Memory \& Cognition.

Frankel, M. T., \& Rollins, H. A. (1986). Associative and categorical hypotheses of organization in the free recall of adults and children. Journal of Experimental Child Psychology, 40, 304-318.

Gardner, H., Boller, F., Moreines, J., \& Butters, N. (1973). Retrieving information from Korsakoff patients: Effects of categorical cues and reference to the task. Cortex, 9, 165-175.

Graf, P., \& SChaCter, D. L. (1985). Implicit and explicit memory for new associations in normal and amnesic subjects. Journal of Experimental Psychology: Learning, Memory, \& Cognition, 11, 501-518.

Graf, P., Shimamura, A. P., \& SQuire, L. R. (1985). Priming across modalities and priming across category levels: Extending the domain of preserved function in amnesia. Journal of Experimental Psychology: Learning, Memory, \& Cognition, 11, 386-396.

JACOBY, L. L. (1983). Remembering the data: Analyzing interactive processes in reading. Journal of Verbal Learning \& Verbal Behavior, 22, 485-508.

KolB, B., \& Whishaw, I. Q. (1990). Fundamentals of human neuropsychology. New York: W. H. Freeman.

McCauley, C., Weil, C. M., \& Sperber, R. D. (1977). The development of memory structure as reflected by semantic-priming effects. Journal of Experimental Child Psychology, 22, 511-518.

Morris, C. D., BranSFORD, J. D., \& FranKS, J. J. (1977). Levels of processing versus transfer appropriate processing. Journal of Verbal Learning \& Verbal Behavior, 16, 519-533.

OGAWA, T. (1972). 52 kategori ni zokusuro go no shutsugen hindohyou [Frequency association norms for 50 categories]. Jinbun Ronkyu, 22, 1-61.

RAPPOLD, V. A., \& HASHTROUdI, S. (1991). Does organization improve priming? Journal of Experimental Psychology: Learning, Memory, \& Cognition, 17, 103-114.

Roediger, H. L., III, \& BLAXton, T. A. (1987). Retrieval modes produce dissociations in memory for surface information. In D. Gorfein \& R. R. Hoffman (Eds.), Memory and cognitive processes: The Ebbinghaus Centennial Conference (pp. 349-379). Hillsdale, NJ: Erlbaum.

Roediger, H. L., III, \& MCDermotT, K. B. (1993). Implicit memory in normal human subjects. In F. Boller \& J. Grafman (Eds.), Handbook of neuropsychology (pp. 63-131). Amsterdam: Elsevier.

Roediger, H. L., III, SRINIVAS, K., \& Weldon, M. S. (1989). Dissociations between implicit measures of retention. In S. Lewandowsky, J. C. Dunn, \& K. Kirsner (Eds.), Implicit memory: Theoretical issues (pp. 67-84). Hillsdale, NJ: Erlbaum.

Roediger, H. L., III, Weldon, M. S., \& Challis, B. H. (1989). Explaining dissociations between implicit and explicit measures of retention: A processing account. In H. L. Roediger III \& F. I. M. Craik (Eds.), Varieties of memory and consciousness: Essays in honor of Endel Tulving (pp. 3-41). Hillsdale, NJ: Erlbaum.

SCHACTER, D. L., BOWERS, J., \& BOOKER, J. (1989). Intention, awareness, and implicit memory. In H. L. Roediger III \& F. I. M. Craik (Eds.), Implicit memory: Theoretical issues (pp. 47-65). Hillsdale, NJ: Erlbaum.

Shimamura, A. P., \& Squire, L. R. (1984). Paired-associate learning and priming effects in amnesia: A neuropsychological approach. Journal of Experimental Psychology: General, 112, 556-570.

SRINIVAS, K., \& ROEDIGER, H. L., III (1990). Classifying implicit memory tests: Category association and anagram solution. Journal of Memory \& Language, 29, 389-412.

Tulving, E., \& OsLer, S. (1968). Effectiveness of retrieval cues in memory for words. Journal of Experimental Psychology, 75, 593601.

WELDON, M. S., \& RoEDIGER, H. L., III (1987). Altering retrieval demands reverses the picture superiority effect. Memory \& Cognition, $15,269-280$.

(Manuscript received March 29, 1994; revision accepted for publication August 22, 1994.) 